\title{
The Effect of Intravenous Paracetamol on Postoperative Pain after Lumbar Discectomy
}

\author{
Mohammad Shimia ${ }^{1}$, Masoud Parish ${ }^{2}$, Naghi Abedini ${ }^{2}$ \\ ${ }^{I}$ Department of Neurosurgery, Tabriz University of Medical Sciences, Tabriz, Iran \\ ${ }^{2}$ Department of Anesthesiology, Tabriz University of Medical Sciences, Tabriz, Iran
}

Study Design: A randomized, double-blinded controlled trial.

Purpose: Postoperative pain relief especially using analgesic drugs with minimal side effects has considerable clinical importance. This study aimed to examine the effect of intravenous paracetamol on pain relief after lumbar discectomy as a major surgery.

Overview of Literature: Patients undergoing lumbar discectomy experience a high degree of lumbar pain. Some authors emphasize the use of intravenous paracetamol to improve postoperative pain and increase patients' satisfaction following this surgery

Methods: Fifty-two patients scheduled for lumbar discectomy were randomly allocated into two groups: a group that received intravenous paracetamol ( $1 \mathrm{~g} / 100 \mathrm{~mL}$ normal saline) within the last 20 minutes of surgery as the case group $(\mathrm{n}=24)$ and a group that received sodium chloride $0.9 \% 100 \mathrm{~mL}$ as the control group ( $\mathrm{n}=28$ ). Postoperative pain was assessed at 1, 6, 12, 18, and 24 hours after surgery by a visual analogue scale (VAS). The dosage of the administered opioid (morphine), as well as drug-related side effects within the first 24 hours after surgery were also recorded.

Results: The mean VAS score was significantly lower in the paracetamol group than the controls for all of the assessed time points. Although the dose of the administered morphine was numerically lower in the paracetamol group, this difference was not statistically significant (5.53 $4.49 \mathrm{~mL}$ vs. $7.85 \pm 4.17 \mathrm{~mL})$.

Conclusions: Intravenous paracetamol as a non-opioid analgesic can relieve postoperative pain in patients undergoing lumbar discectomy; however, its use alone may not represent the best regimen for reducing the needed dose of opioids after operation.

Keywords: Analgesia; Paracetamol; Lumbar discectomy; Pain; Morphine

\section{Introduction}

Inadequate control of pain leads to some inappropriate physiological sequences including delayed gastrointestinal and respiratory functions [1]. Unrelieved pain can increase the stress response, affecting the immune system and resulting in delayed healing and improvement $[2,3]$ as well as triggering chronic pain syndrome [4]. In this context, some compound therapeutic drug regimens that cause synergistic effects on pain relief have been recommended postoperatively. Because low dosages of these drugs are usually administered, their related side effects can be potentially minimized [5].

Paracetamol is a selective cyclooxygenase-2 (COX2) inhibitor that exerts a central analgesic effect through the activation of the descending serotonergic pathways [6]. This drug is an effective analgesic agent and has no side effects that are observable in opioids or non steroi-

Received Jul 14, 2013; Revised Aug 13, 2013; Accepted Aug 13, 2013

Corresponding author: Masoud Parish

Department of Neurosurgery, Shohada Hospital, Tabriz University of Medical Sciences,

El-Goli Road, Postal code 5169664339, Tabriz, Iran

Tel: +98-914-4022711, Fax: +984113854584, E-mail: masoudparish@yahoo.com 
dal anti-inflammatory drugs (NSAIDs) [7]. Intravenous paracetamol is useful for relieving postoperative pain. It has been suggested that the use of this drug might have higher analgesic effects and lower the need for postoperative opioids compared with other analgesics, and therefore, its administration seems to be preferable in various type of surgeries [8].

Patients undergoing lumbar discectomy usually experience much lumbar pain and commonly have delayed hospital discharge and return to work. Some authors have emphasized the use of intravenous paracetamol to improve postoperative pain and increase patients' satisfaction following this type of surgery [9-12]. For increasing its beneficial effects on pain relief, paracetamol can be given as a rectal, oral, or intravenous preparation [13]; however, the route of administration can lead to different levels of effectiveness because of the differences in absorption and the time to reach peak plasma levels. In the rectal method, absorption of paracetamol can be unpredictable and its biomedical level varies widely between $24 \%$ and $98 \%$ [14]. Paracetamol is generally considered to be an inhibitor of the synthesis of prostaglandins related to pain and hypersensitivity [15]. The apparent selectivity of paracetamol may be due to inhibition of COX-2dependent pathways, however COX-3, a splice variant of COX-1, has been recently suggested to be the site of action of paracetamol, especially for its effects on pain relief $[16,17]$. Intravenous paracetamol can be used as a formulation during or after anesthesia. This drug has an analgesic effect that starts within 0.5 to 1 hour and lasts 6 to 8 hours. This is consistent with the plasma half-life of 2.7 hours. The elimination half-life is 1 to 4 hours and it can be used as 1-g infusions, with a maximal daily dose of 4 grams for adults $[18,19]$. It has been demonstrated that the co-administration of paracetamol and opioids can be much more effective than was previously thought $[20,21]$.

This study aimed to examine the effect of intravenous paracetamol on pain relief after the major surgery of lumbar discectomy.

\section{Materials and Methods}

In a randomized double-blinded clinical trial, 52 patients scheduled for elective lumbar discectomy were included in the study. All patients aged older than 20 years (range, 21-78 years) and had Americn Society of Anesthesiologists physical status I and II. None of the patients had sensitivity to the administered drugs. Those with a history of chronic liver or kidney diseases, any premedication such as trinitroglycerin, narcotics, benzodiazepines, or clonidine or those who refused to participate in the study were excluded. The trial was registered with and approved by the institutional ethical review board and the local ethics committee of the Tabriz University of Medical Sciences and Iranian Registry of Clinical Trials. On arrival to the operating room, standard monitoring was established (pulse oximetry, electrocardiography, and noninvasive arterial blood pressure monitoring). After obtaining informed consent, the study patients were randomly allocated into two groups: a group that received intravenous paracetamol ( $1 \mathrm{~g} / 100 \mathrm{~mL}$ normal saline) within the last 20 minutes of surgery, as the case group $(\mathrm{n}=24)$; and a group that received sodium chloride $0.9 \% 100 \mathrm{~mL}$, as the control group $(\mathrm{n}=28)$. All local anesthetic solutions and adjuvant drugs were prepared by an anesthesiologist who was not involved in the performance of the study agents, patient care, or data collection. The patients were familiarized with a 10-point visual analogue scale (VAS) $(0$ indicated no pain and 10 indicated the worse imaginable pain) for assessing pain levels at different time points $(1,6$, 12,18 , and 24 hours after surgery). The dosages of morphine administered postoperatively within 24 hours after the operation were recorded in each group. Drug side effects such as nausea, vomiting, dizziness, constipation and urinary retention were also evaluated and compared across the two groups.

The results were reported as the mean \pm standard deviation for the quantitative variables and percentages for the categorical variables. The groups were compared using the $t$ test or Mann-Whitney $U$ test for the continuous variables and the chi-square test (or Fisher's exact test if required) for the categorical variables. $p$-values of 0.05 or less were considered statistically significant. All the statistical analyses were performed using SPSS ver. 16.0 (SPSS Inc., Chicago, IL, USA).

\section{Results}

The overall mean age of the study population was $49.60 \pm 12.93$ years (median, 47 years; range, $21-78$ years). Among them, 24 (46.2\%) were male. The study participants who received intravenous paracetamol and those who were administered only sodium chloride $0.9 \%$ were similar with respect to their average age $(46.50 \pm 14.07$ 
Table 1. Pain severity within 24-hour after surgery

\begin{tabular}{lccc} 
Visual analogue scale & Paracetamol group $(\mathrm{n}=24)$ & control group $(\mathrm{n}=28)$ & $p$-value \\
\hline $1 \mathrm{hr}$ after surgery & $6.66 \pm 1.55$ & $7.92 \pm 1.43$ & $<0.01$ \\
\hline $6 \mathrm{hr}$ after surgery & $6.12 \pm 1.48$ & $7.14 \pm 1.32$ & 0.01 \\
\hline $12 \mathrm{hr}$ after surgery & $5.00 \pm 1.47$ & $5.96 \pm 1.52$ & 0.02 \\
\hline $18 \mathrm{hr}$ after surgery & $4.29 \pm 1.23$ & $5.07 \pm 1.11$ & 0.02 \\
\hline $24 \mathrm{hr}$ after surgery & $2.45 \pm 1.14$ & $3.42 \pm 1.42$ & 0.01 \\
\hline
\end{tabular}

Values are presented as mean \pm standard deviation.

years vs. $52.25 \pm 11.46$ years) and the male to female ratio. There was a significant difference in the mean of the pain score for pain measured over time between the two groups ( $t$-test) (Table 1) in that the mean VAS score was significantly lower in the paracetamol group than the controls at all of the assessed time points. The assessment of trends of changes in the pain score across the two groups showed that there were no significant differences between them (the repeated measure analysis of variance test) (Fig. 1). Although the dose of administered morphine was numerically lower in the paracetamol group, this difference was not statistically significant $(5.53 \pm 4.49$ $\mathrm{mg}$ vs. $7.85 \pm 4.17 \mathrm{mg}$ ). No significant drug-related side effect was detected in either group.

\section{Discussion}

In the current study, it was found that the administration of intravenous paracetamol led to reduced postoperative pain as well as fewer requests for postoperative opioids. In our study, intravenous paracetamol was administered alone; however, this regimen can also be combined with opioids or NSAIDs [8]. We showed that those who were administered paracetamol experienced a lower level of

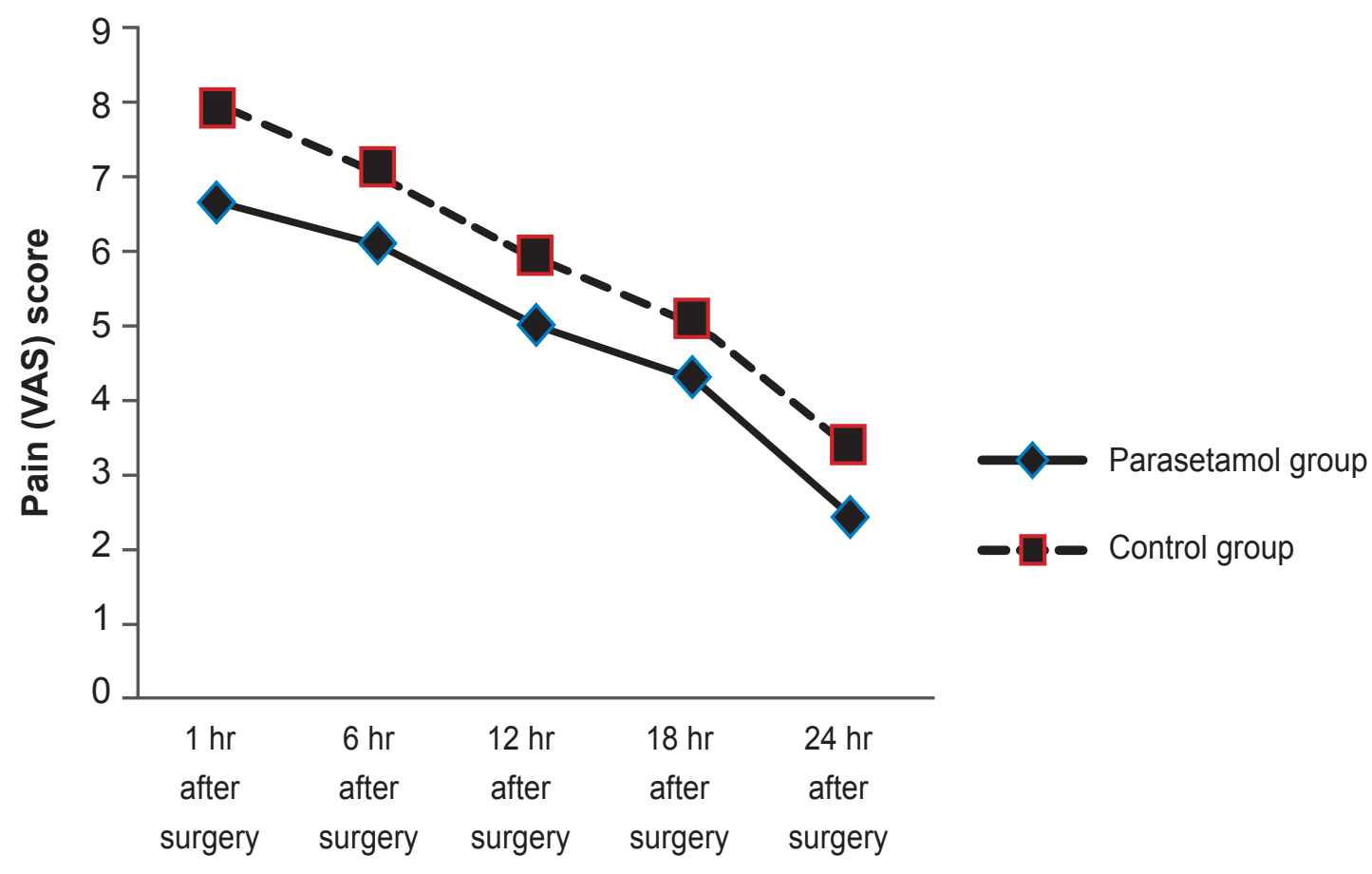

Time points

Fig. 1. Trend of the changes in the pain score in the two intervention groups. VAS, visual analogue scale. 
postoperative pain as evidenced by the lower mean VAS score within 24 hours after surgery. In a study by Korkmaz Dilmen et al. [10], similar findings were observed regarding the effects of intravenous paracetamol on postoperative pain relief. In another study by Cakan et al. [9], pain severity was significantly lower in the intravenous paracetamol group than the controls, and the former group reported excellent pain reduction after surgery. Also, Memis et al. [22] showed that the use of intravenous paracetamol, especially when it was combined with morphine, could result in a lower pain score as well as a lower rate of postoperative drug-related side effects in patients undergoing major surgeries. In a similar study by Cakan et al. [9] on patients undergoing lumbar discectomy, the pain level was considerably lower in the group which was administered intravenous paracetamol, and there was also higher patient satisfaction and less drug-related vomiting in this group. In fact, their study also showed that intravenous paracetamol not only effectively reduced postoperative pain severity but also increased patients' satisfaction with their postoperative pain relief. Also, the fact that some other studies showed no significant difference in the pain-relieving effect between the paracetamol and placebo groups might be due to the small sample sizes in the studies or the observational nature of these studies [22]. In our study, although the doses of the administered opioids were lower in the intravenous paracetamol group, this difference was not statistically significant. A similar result was revealed in the study by Cakan, et al. [9]. In the Korkmaz Dilmen et al. [10] study, although the doses of morphine used were significantly lower in the group that was administered paracetamol 12 hours after the operation, the accumulative dose of morphine was similar during the first 24 hours after surgery. Similar results were also reported in the study by Grundmann et al. [23]. However, the accumulative dose of postoperatively used opioids was reduced in the group which received paracetamol, even during the first 48 hours after the operation $[11,12]$. It seems that the conflicting results can be related to the analgesic regimens used before and during the operations as well as differences in the anesthetic regimens and the exclusion criteria defined in the studies.

In the present study, we did not observe any drugrelated side effects and this could be good support for the appropriateness of the administered dose of paracetamol used in our trial. In Fletcher et al.s [12] study, the overall prevalence of drug side effects was comparable between the two study groups. In another study by Grundmann et al. [23], postoperative shivering was observed in only one patient compared with the six affected ones in the control group. Cakan et al. [9] also showed a lower prevalence of postoperative vomiting in the group that received paracetamol. Totally, it seems that because of the considerably lower pain severity, the lower incidence of side effects as well as the higher rate of satisfaction with the pain relief, the use of intravenous paracetamol is potentially safe, effective, and satisfactory in patients undergoing lumbar discectomy.

\section{Conclusions}

In summary, our study shows that intravenous paracetamol can relieve postoperative pain in patients undergoing lumbar discectomy; however, its use alone may not represent the best regimen for reducing the dose of opioids needed after an operation. But this finding might be due to the small sample size of this study, and thus, further studies with greater population sizes should be performed. In fact, the beneficial effect of paracetamol was examined in comparison with sodium chloride, and thus its effect cannot be generalized to all cost-effective drugs. However, because of the low cost of paracetamol as well as the lower incidence of side effects compared to the drugs commonly used such as morphine, the use of the former drug is preferred. The use of paracetamol can also effectively reduce drug-induced side effects and thus postoperative complications.

\section{Conflict of Interest}

No potential conflict of interest relevant to this article was reported.

\section{Acknowledgments}

This study was supported by the Tabriz University of Medical Sciences. We thank the University authorities who offered critical administrative support and managerial services in carrying out the study and also all researchers for their help and support.

\section{References}

1. Carr DB. Preempting the memory of pain. JAMA 
1998;279:1114-5.

2. Beilin B, Shavit Y, Trabekin E, et al. The effects of postoperative pain management on immune response to surgery. Anesth Analg 2003;97:822-7.

3. Shavit Y, Weidenfeld J, DeKeyser FG, et al. Effects of surgical stress on brain prostaglandin E2 production and on the pituitary-adrenal axis: attenuation by preemptive analgesia and by central amygdala lesion. Brain Res 2005;1047:10-7.

4. DeLeo JA, Tanga FY, Tawfik VL. Neuroimmune activation and neuroinflammation in chronic pain and opioid tolerance/hyperalgesia. Neuroscientist 2004;10:40-52.

5. Kehlet H, Dahl JB. The value of "multimodal" or "balanced analgesia" in postoperative pain treatment. Anesth Analg 1993;77:1048-56.

6. Pickering G, Loriot MA, Libert F, Eschalier A, Beaune P, Dubray C. Analgesic effect of acetaminophen in humans: first evidence of a central serotonergic mechanism. Clin Pharmacol Ther 2006;79:371-8.

7. Bannwarth B, Pehourcq F. Pharmacologic basis for using paracetamol: pharmacokinetic and pharmacodynamic issues. Drugs 2003;63:5-13.

8. Macario A, Royal MA. A literature review of randomized clinical trials of intravenous acetaminophen (paracetamol) for acute postoperative pain. Pain Pract 2011;11:290-6.

9. Cakan T, Inan N, Culhaoglu S, Bakkal K, Basar H. Intravenous paracetamol improves the quality of postoperative analgesia but does not decrease narcotic requirements. J Neurosurg Anesthesiol 2008;20:169-73.

10. Korkmaz Dilmen O, Tunali Y, Cakmakkaya OS, et al. Efficacy of intravenous paracetamol, metamizol and lornoxicam on postoperative pain and morphine consumption after lumbar disc surgery. Eur J Anaesthesiol 2010;27:428-32.

11. Toygar P, Akkaya T, Ozkan D, Ozel O, Uslu E, Gumus $H$. Does iv paracetamol have preemptive analgesic effect on lumber disc surgeries? Agri 2008;20:14-9.

12. Fletcher D, Negre I, Barbin C, et al. Postoperative analgesia with i.v. propacetamol and ketoprofen combination after disc surgery. Can J Anaesth 1997;44:479-
85.

13. Malaise O, Bruyere O, Reginster JY. Intravenous paracetamol: a review of efficacy and safety in therapeutic use. Future Neurol 2007;2:673-88.

14. Oscier C, Bosley N, Milner Q. Paracetamol: a review of three routes of administration. Update Anaesth 2007;2:112-4.

15. Miller RD. Miller's Anesthesia. 6th ed. Philadelphia: Churchill Livingstone; 2005.

16. Chandrasekharan NV, Dai H, Roos KL, et al. COX-3, a cyclooxygenase-1 variant inhibited by acetaminophen and other analgesic/antipyretic drugs: cloning, structure, and expression. Proc Natl Acad Sci U S A 2002;99:13926-31.

17. Beck DH, Schenk M, Doepfmer U, Kox WJ. Rectal paracetamol has a significant morphine-sparing effect after hysterectomy. Br J Anaesth 2000;85:658-9.

18. Stephan A, Schung DA. Effect of general anesthesia and surgery on the kinetics of intravenous proparacetamol. Br J Anaesth 1999;82(Suppl 1): 21-5.

19. Keays R, Harrison PM, Wendon JA, et al. Intravenous acetylcysteine in paracetamol induced fulminant hepatic failure: a prospective controlled trial. BMJ 1991;303:1026-9.

20. Schug SA, Sidebotham DA, McGuinnety M, Thomas J, Fox L. Acetaminophen as an adjunct to morphine by patient-controlled analgesia in the management of acute postoperative pain. Anesth Analg 1998;87:36872.

21. Warner TD, Mitchell JA. Cyclooxygenase-3 (COX3): filling in the gaps toward a COX continuum? Proc Natl Acad Sci U S A 2002;99:13371-3.

22. Memis D, Inal MT, Kavalci G, Sezer A, Sut N. Intravenous paracetamol reduced the use of opioids, extubation time, and opioid-related adverse effects after major surgery in intensive care unit. J Crit Care 2010; 25:458-62.

23. Grundmann U, Wornle C, Biedler A, Kreuer S, Wrobel M, Wilhelm W. The efficacy of the non-opioid analgesics parecoxib, paracetamol and metamizol for postoperative pain relief after lumbar microdiscectomy. Anesth Analg 2006;103:217-22. 